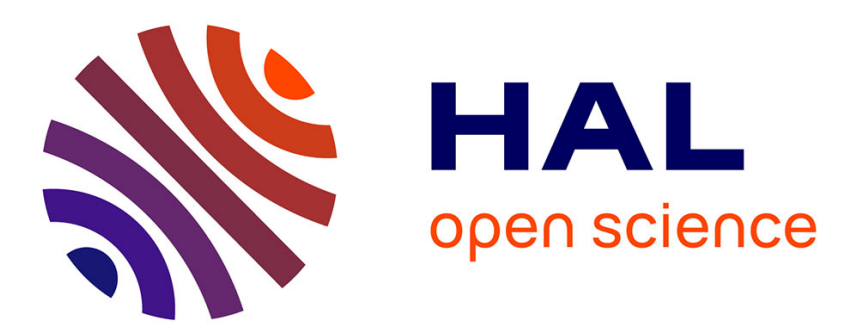

\title{
Implicit modeling of folds and overprinting deformation
}

Gautier Laurent, Laurent Ailleres, Lachlan Grose, Guillaume Caumon, Mark W. Jessell, Robin Armit, Laurent Laurent

\section{To cite this version:}

Gautier Laurent, Laurent Ailleres, Lachlan Grose, Guillaume Caumon, Mark W. Jessell, et al.. Implicit modeling of folds and overprinting deformation. Earth and Planetary Science Letters, 2016, 456, pp.26 - 38. 10.1016/j.epsl.2016.09.040 . hal-01390858

\section{HAL Id: hal-01390858 \\ https://hal.univ-lorraine.fr/hal-01390858}

Submitted on 23 Oct 2017

HAL is a multi-disciplinary open access archive for the deposit and dissemination of scientific research documents, whether they are published or not. The documents may come from teaching and research institutions in France or abroad, or from public or private research centers.
L'archive ouverte pluridisciplinaire HAL, est destinée au dépôt et à la diffusion de documents scientifiques de niveau recherche, publiés ou non, émanant des établissements d'enseignement et de recherche français ou étrangers, des laboratoires publics ou privés. 


\title{
Implicit Modeling of Folds and Overprinting Deformation
}

\author{
G. Laurent*1,2 ${ }^{*}$ Laurent Ailleres ${ }^{1}$, Lachlan Grose ${ }^{1}$, Guillaume Caumon ${ }^{2}$, Mark Jessell ${ }^{3}$, and Robin Armit ${ }^{1}$ \\ ${ }^{1}$ School of Earth, Atmosphere and Environment, Monash University, Australia \\ ${ }^{2}$ GeoRessources (UMR 7359), Université de Lorraine-ENSG, CNRS, CREGU, Campus Brabois, BP 10162, 54505 Vandoeuvre-lès-Nancy Cedex, France \\ ${ }^{3}$ University of Western Australia, Centre for Exploration Targeting, M006, 35 Stirling Highway, Crawley WA 6009 Australia
}

\begin{abstract}
Three-dimensional structural modeling is gaining importance for a broad range of quantitative geoscientific applications. However, existing approaches are still limited by the type of structural data they are able to use and by their lack of structural meaning. Most techniques heavily rely on spatial data for modeling folded layers, but are unable to completely use cleavage and lineation information for constraining the shape of modeled folds. This lack of structural control is generally compensated by expert knowledge introduced in the form of additional interpretive data such as cross-sections and maps. With this approach, folds are explicitly designed by the user instead of being derived from data. This makes the resulting structures subjective and deterministic.

This paper introduces a numerical framework for modeling folds and associated foliations from typical field data. In this framework, a parametric description of fold geometry is incorporated into the interpolation algorithm. This way the folded geometry is implicitly derived from observed data, while being controlled through structural parameters such as fold wavelength, amplitude and tightness. A fold coordinate system is used to support the numerical description of fold geometry and to modify the behavior of classical structural interpolators. This fold frame is constructed from fold-related structural elements such as axial foliations, intersection lineations, and vergence. Poly-deformed terranes are progressively modeled by successively modeling each folding event going backward through time.

The proposed framework introduces a new modeling paradigm, which enables the building of threedimensional geological models of complex poly-deformed terranes. It follows a process based on the structural geologist approach and is able to produce geomodels that honor both structural data and geological knowledge.
\end{abstract}

\section{Keywords}

3D Modeling

Implicit Modeling

Geological Structures

Fold

Foliation

Vergence

\section{INTRODUCTION}

Three-dimensional modeling of geological structures is becoming an essential component of quantitative geoscientific research. For example, it helps to address challenges in sediment budget assessment [Guillocheau et al., 2012], seismic mechanism and seismic hazard studies [Li et al., 2014, Shaw et al., 2015], and natural resources characterization [Cox et al., 1991, Mueller et al., 1988, Vollger et al., 2015]. However, the construction of a three-dimensional structural model from available observations remains a challenging task. 3D structural modeling techniques are essentially data-driven processes honoring spatial observations [Jessell et al., 2014]. In most cases, these techniques rely on expert knowledge for overcoming the sparsity and uncertainty of available observations [Maxelon et al., 2009]. Structural geology concepts are generally incorporated in the process through interpretive elements in the form of maps, cross-sections or control points [Caumon et al., 2009]. Because these elements cannot be easily changed and represent the interpretation of the modeler, they also make this process slow, deterministic, and difficult to reproduce. Any expert editing is subjective and may introduce human bias [Bond et al., 2007]. This limits the understanding of uncertainties, which have to be assessed for a structural model to fulfill its role [Bond, 2015, Caumon, 2010, Lindsay et al., 2012, Wellmann and Regenauer-Lieb, 2012]. One way to study uncertainties consist in producing a suite of possible models instead of a single deterministic one, but this approach is limited by the nec- essary expert editing of classical structural modeling approaches. Moreover, structural modeling techniques are generally limited to stratigraphic contact location and bedding orientation [Calgagno et al., 2008, Caumon et al., 2013]. Some types of structural data are often ignored [Maxelon et al., 2009, Jessell et al., 2010, 2014], and part of the knowledge collected in the field is actually lost in the process of creating a geological model. A significant challenge is to formalize conceptual information and combine these with all observations.

While the modeling of faults using implicit approach is relatively developed [Calgagno et al., 2008, Cherpeau et al., 2010a,b, 2012, Cherpeau and Caumon, 2015, Laurent et al., 2013], folds have received little attention. Only few contributions provide solutions to locally control fold-related geometries in interpolation methods [Caumon et al., 2013, Hjelle et al., 2013, Mallet, 2004, Maxelon et al., 2009]. This is particularly difficult for hard rock terranes, where the continuity of stratigraphic layers and foliations are difficult to establish because of overprinting deformation events [Forbes et al., 2004, Ramsay, 1962] (Fig. 1).

A variety of structural modeling approaches exists, which combine numerical methods of interpolation [Calgagno et al., 2008, Chilès et al., 2004, Cowan et al., 2003, Frank et al., 2007, Hillier et al., 2014, Lajaunie et al., 1997, Mallet, 1992, 2014]. Interpolation techniques proceed by geometric smoothing between data points. They perform well for dense data, but generate minimal surfaces when data are sparse, thus minimizing the curvature of the produced surfaces. However, folds are precisely charac- 


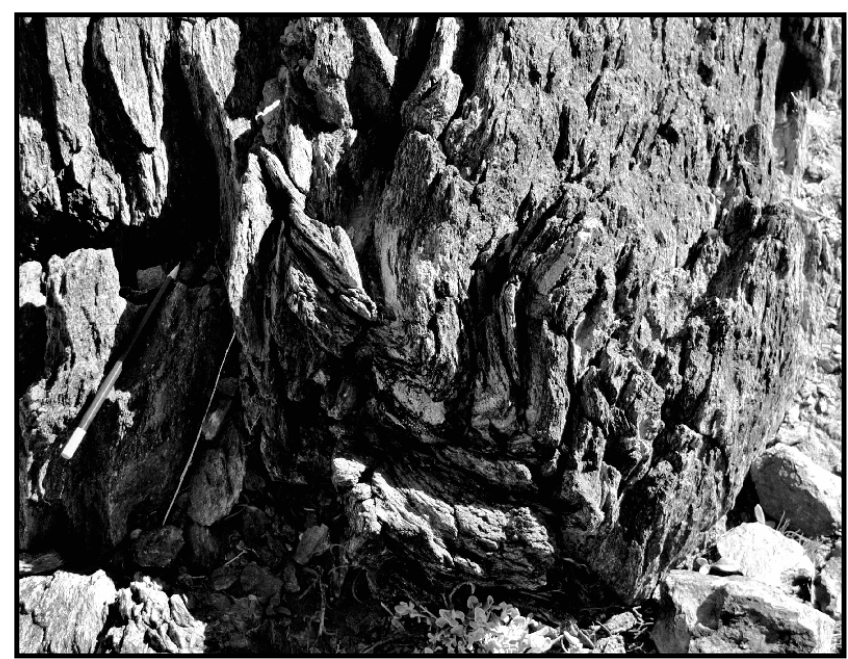

A. Outcrop near Eldee Creek, Australia

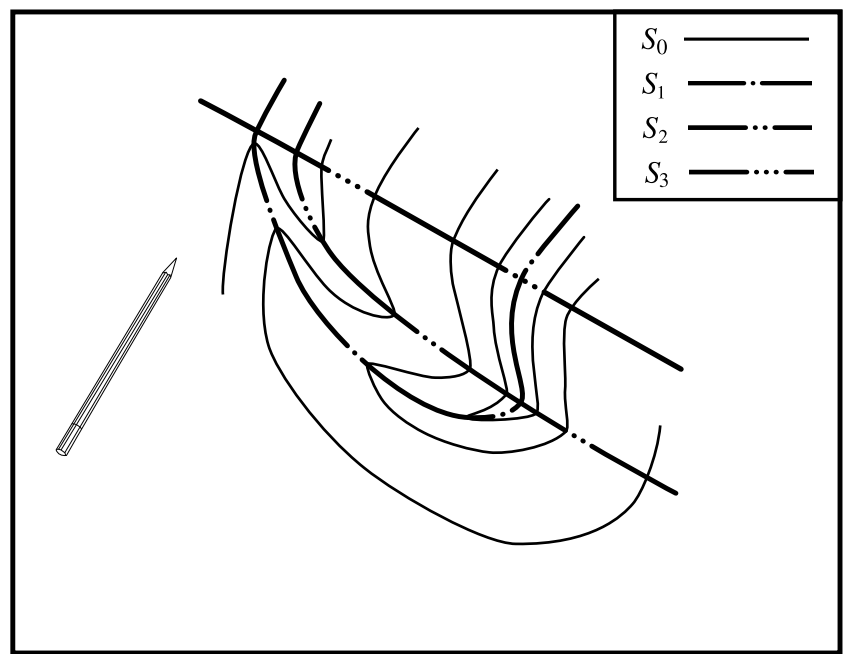

B. Structural interpretation

Figure 1 Interference between multiple fold events. A: photography of an outcrop in Eldee Creek, Broken Hill block, Australia, showing complex bedding/cleavage geometry and overprinting relationships. B: structural analysis reveals at least three successive folding events with associated foliations. Note that the complexity of the geometry increases with the age of each deformation event. terized by specific, non-minimal curvature patterns [Lisle and Toimil, 2007, Mynatt et al., 2007].

We propose a method of interpolation which is designed to bridge the gap between data-driven and knowledge-driven methods, and addresses: (1) A better use of available data, in particular structural information related to folds. (2) The development of a time-aware data-driven method that takes into account the whole folding history. This is achieved by modifying the behavior of interpolation algorithms and incorporating a fold description in the interpolation process.

Our description of folding is based on a fold frame (Section 2), whose construction relies on observable structural elements (e.g. axial foliation). Deformation events are modeled successively by locally characterizing the relative orientation of their structural elements (Section 3). This modeling strategy is implemented in the framework of discrete implicit interpolation techniques [Caumon et al., 2013, Collon-Drouaillet et al., 2015, Frank et al., 2007, Mallet, 2014] through a set of specific numerical constraints (Section 4). The principles of this modeling strategy are illustrated on various examples of increasing complexity (Section 5).

For simplicity, we focus on the deformation of a conformable stratigraphic sequence, excluding faults, intrusions or unconformities. These geological features may be handled as proposed by Calgagno et al. [2008], Caumon et al. [2013], Laurent et al. [2013] or Rфe et al [2014].

\section{Structural description Of Folded structures}

This section presents some basic structural concepts and structural elements associated with folds. From there, we define a coordinate system used for parameterizing fold geometry and guiding fold interpolation.

\section{Structural data and notations}

Various structural observations related to folding may be used as data for building a geological model:

- Stratigraphic observations: They comprise the locations where a given stratigraphic contact is observed, and the orientation of bedding. These two observations are not necessarily recorded at the same locations. For example, bedding orientation may also be observed inside a given layer.

- Direct structural element observations: Some of the fold features can be directly observed, e.g. hinge locations, fold axis directions or axial surface orientations. These features can be observed along fold axial surfaces.

- Indirect structural element observations: Observations of axial surface cleavages, intersection lineations and vergence carry indirect information about fold parameters (e.g. fold amplitude, tightness, wavelength and location of the fold hinges).

The following symbols are used to refer to different stratigraphic and fold features that are considered in this study: D: deformation event, F: folding event, S: foliation field (generally a cleavage associated with a fold axial surface), L: intersection lineation (generally associated with a fold axis).

Each of these features may be indexed by a number that represents the associated relative deformation event (e.g. $S_{1}$ for the axial foliation of $D_{1}$ ). Bedding is referred to as $S_{0}$. When dealing with the relationship between successive folding events, the current event is denoted $\mathrm{F}_{i}$, and any previous or later fold are respectively referred to as $\mathrm{F}_{i-1}$ and $\mathrm{F}_{i+1}$. 
In our framework, foliations are mathematically represented by scalar fields. Each foliation surface corresponds to an iso-surface of the corresponding field. Lineations are represented by unit vector fields where the vectors are locally parallel to the lineation direction.

The symbol $\dagger$ is used to denote user defined parameters or to distinguish local observations of a given feature from the result of its interpolation. For example, observations of bedding are denoted $S_{0}^{\dagger}$. The orientations of foliations are represented by the gradient of the corresponding scalar field, denoted $\nabla S$. For example, observations of the orientation of a foliation $S_{1}$ are denoted $\nabla S_{1}^{\dagger}$.

\section{Fold geometry, structural elements and finite strain}

Folds are continuous geological structures describing a curved geometry of a geological foliation (e.g. bedding, tectonic cleavages). Fold geometry is commonly characterized by: (1) a hinge, defined as the location of maximal curvature of the deformed foliation; (2) an axial surface, which separates opposed limbs and contains fold hinges; (3) a fold axis, which is defined by the intersection between the deformed foliation and the axial surface; (4) a fold movement direction, which is defined as the direction within the axial surface in which the deformed foliation is sheared or deviated from its original geometry [Grasemann et al., 2004, Ramsay, 1962].

The geometry of a fold relates to the local principal finite strain directions in which the corresponding folding event developed. These directions are denoted $\vec{X}, \vec{Y}$, and $\vec{Z}$, and respectively correspond to the directions of greatest, intermediate, and least elongation. They are denoted with curved arrow as they represent curvilinear axes. Folds develop with their axial surfaces orthogonal to the greatest shortening direction $\widetilde{Z}$. Fold movement direction is generally parallel to the greatest elongation direction $\overrightarrow{\mathrm{X}}$. For cylindrical folds, the fold axis would generally align with the intermediate direction $\overrightarrow{\mathrm{Y}}$. When folds are non-cylindrical, the actual fold axis direction may vary and locally deviates from $\widetilde{Y}$. This deviation can become very intense in the case of sheath folds.

Different structural elements may also form as a result of the finite strain associated with a folding event $\mathrm{F}_{i}$ : (1) an axial foliation $\mathrm{S}_{i}$, orthogonal to $\overrightarrow{\mathrm{Z}}$ and parallel to $\overrightarrow{\mathrm{X}}, \overrightarrow{\mathrm{Y}}$ and the axial surfaces of a fold series; (2) an intersection lineation $\mathrm{L}_{i}$, which results from the intersection between $S_{i}$ and $S_{i-1}$, and is parallel to the fold axis; (3) a stretching lineation $\mathrm{T}_{i}$, which may develop relatively parallel to $S_{i}$ in the $\vec{X}$ direction. These structural elements may be observed in the field and should be used for constraining possible fold geometries.

\section{Defining a curvilinear fold frame}

The principal finite strain directions are intimately related to folding and provide a consistent framework for describing fold geometry and structural elements. We use this concept to define a coordinate system, referred to as fold frame. It consists in three curvilinear axes, which correspond to each finite strain direction, $\overrightarrow{\mathrm{X}}, \overrightarrow{\mathrm{Y}}$, and $\widetilde{\mathrm{Z}}$ (Fig. 2A). The fold frame locates each spatial position with respect to the structure of the fold, and makes it easier to parameterize the fold geometry, especially when several interfering folding events are considered (Fig. 1). Each axis bears a coordinate represented by a 3D scalar field, respectively referred to as $x, y$ and $z$ (Fig. 2B).

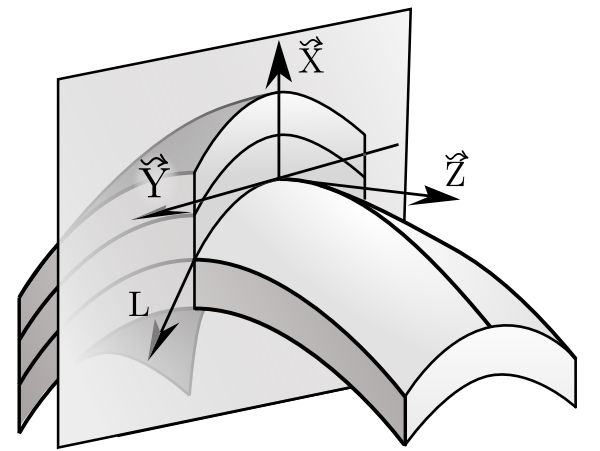

A. Curvilinear fold frame directions

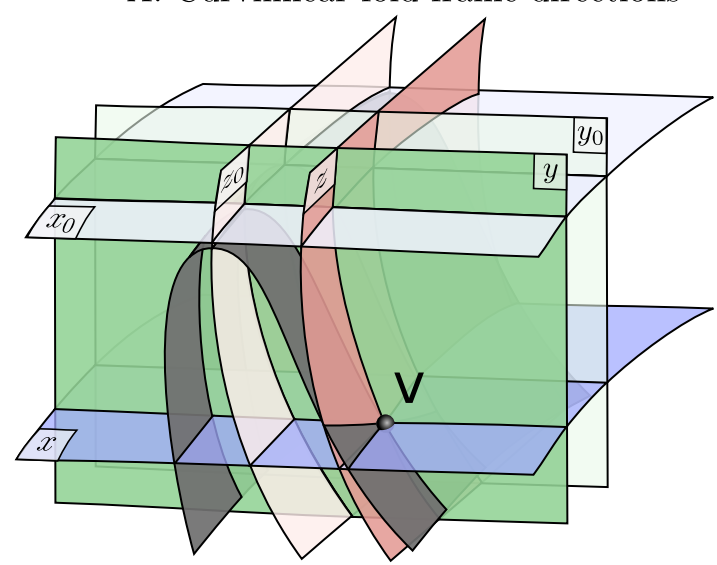

B. Curvilinear fold frame: $x, y, z$ coordinates

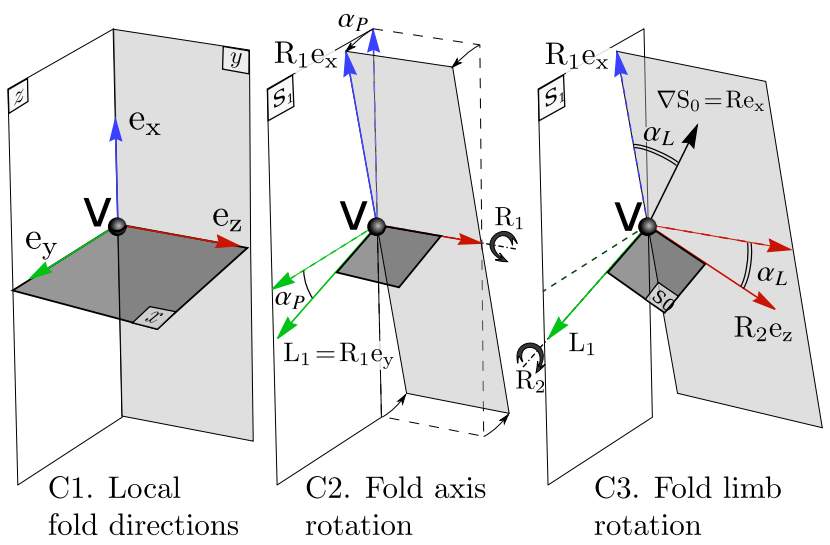

Figure 2 Curvilinear fold frame. A: The fold frame axes with respect to fold geometry and fold axis L. B: The curvilinear fold frame coordinates. C: Three local unit direction vectors $\mathrm{e}_{\mathrm{x}}, \mathrm{e}_{\mathrm{y}}, \mathrm{e}_{\mathrm{z}}(\mathrm{C} 1)$, from which the orientation of the fold axis L1 (C2) and the deformed feature $\nabla S_{0}$ (C3) can be derived.

The $z$ coordinate corresponds to a distance measured along $\widetilde{Z}$ from a reference axial surface of a fold series. This coordinate is convenient for describing the variation of the deformed foliation orientation (Section 2.5).

The $y$ coordinate measures a distance along the intermediate axis $\vec{Y}$ from a reference point (e.g. the apex of the fold, if applicable). It could appear more intuitive to define this second axis and coordinate with respect to the fold axis, but the variations of fold axis orientation for non-cylindrical folds would cause the $y$ coordinate to grow at a varying rate depending on the local orientation of the fold axis. The intermediate finite strain direction $\vec{Y}$ defines a more consistent second spatial coordinate, and provides an appropriate framework for describing the variation of fold axis direction in non-cylindrical folds (Section 2.5).

Finally, the $x$ coordinate corresponds to a distance measured along $\widetilde{\mathrm{X}}$ from a given reference point. This coordinates is partic- 
ularly useful for non-similar folds because their geometry varies with respect to $x$.

Three local direction vectors are implicitly defined by the fold frame for any location $v$ (Fig. 2C1) and are used to define the relative orientation of deformed foliations and structural elements (Section 2.5).

$$
\left\{\begin{array}{l}
\mathrm{e}_{\mathrm{x}}=\nabla x /\|\nabla x\| \\
\mathrm{e}_{\mathrm{y}}=\nabla y /\|\nabla y\| \\
\mathrm{e}_{\mathrm{z}}=\nabla z /\|\nabla z\|
\end{array}\right.
$$

\section{Fold frame and structural elements}

As already acknowledged by Maxelon et al. [2009], axial foliations are a key element to effectively parameterize folds. They are relatively consistent and planar over the studied area, at least for the latest events. In this paper we propose to extend this approach by using the full set of available structural observations for building the fold frame and for constraining the fold geometry parameterization. This process exploits the relative orientation of the successive structural elements as detailed in Section 3.1.

In practice, various geometrical constraints can be derived from structural observations, for example $S_{i}$ and $S_{i-1}$ have to be orthogonal at the fold hinge, and $\mathrm{L}_{i}$ has to be parallel to both $\mathrm{S}_{i}$ and $S_{i-1}$ at any location.

Defining a fold frame may also be useful for folds without visible foliations nor lineations as it provides a powerful additional constraint to guide the interpolation of the geometry of the folds

\section{Defining vergence and fold rotation angles}

The vergence of a given fold is defined anywhere as the relative orientation between the axial foliation $S_{i}$ and the deformed foliation $S_{i-1}$. Vergence indicates the direction towards the next fold closure (Fig. 3). When quantified as an angle $\alpha_{V}$, this measure gives an indication of the relative location of a measurement with respect to the axial surface and the inflexion points of the limbs of a fold. For simplicity, we introduce a fold limb rotation angle $\alpha_{L}$, which is defined as the signed complement of the vergence angle (Fig. 3D).

$$
\alpha_{L}= \begin{cases}\alpha_{V}-\pi / 2, & \text { if } \alpha_{V}>0 \\ \alpha_{V}+\pi / 2, & \text { if } \alpha_{V}<0\end{cases}
$$

The fold limb rotation angle represents a convenient quantity for parameterizing deformed foliation orientation with respect to the fold frame. It presents the properties of: (1) being 0 at the location of axial surfaces, (2) having an increasing absolute value from the hinges to the limb inflexion points, (3) reaching a local minimum or maximum at the location of the limb inflexion point, and (4) having a sign that corresponds to the orientation of the limb with respect to the axial surface. Vergence and fold limb rotation angles can typically be computed from foliation intersection and parasitic folds (Fig. 3BC).

The fold limb rotation angle $\alpha_{L}$ corresponds to a rotation around the intersection of $S_{i}$ and $S_{i-1}$, which is by definition the intersection lineation and fold axis L. With the exception of cylindrical folds, this direction is not parallel to $\widetilde{Y}$. In practice, L can also be described by rotating $\mathrm{e}_{\mathrm{y}}$ around $\mathrm{e}_{\mathrm{z}}$ by an angle $\alpha_{P}$, which is referred to as fold axis rotation angle (Fig. 2B2).

\section{Modeling SUCcessive folding eVents}

The proposed workflow is similar to how structural geologists construct cross-sections in poly-deformed terranes. The interference patterns that may arise in this situation are typical of the relative orientation of the successive fold events [Grasemann et al., 2004, Perrin et al., 1988, Thiessen and Means, 1980]. Figure 1 shows that older foliations have a more complex geometry as they are folded by later folding events. In Fig. $1, S_{3}$ is relatively straight at the scale of the outcrop, $\mathrm{S}_{2}$ is openly folded around $\mathrm{L}_{3}$ fold axis, $S_{1}$ is folded around $L_{2}$ and $L_{3}$, and $S_{0}$ around $L_{1}, L_{2}$ and $\mathrm{L}_{3}$.

When studying this kind of complexly folded structures, it is convenient to analyze the angular relationship between successive structural elements to progressively unravel the structural complexity. We propose to apply a similar sequential approach to structural modeling of complex fold structures.

\section{A fold interpolator based on structural elements}

This section defines a fold interpolator $\mathcal{F}_{i}$ that infers the geometry of a deformed foliation $S_{i-1}$ from a set of observations and fold parameters. $\mathcal{F}_{i}$ works in four steps: (1) building a fold frame based on observations of structural elements; (2) expressing fold angles $\alpha_{P}$ and $\alpha_{L}$ as a function of fold frame; (3) inferring $\nabla \mathrm{S}_{i-1}$ everywhere in space; (4) interpolating $S_{i-1}$ while taking account of $\mathrm{S}_{i-1}^{\dagger}$ and inferred $\nabla \mathrm{S}_{i-1}$.

\section{Building a fold frame}

The process for building a fold frame may vary depending on the structural style and available data. Here we describe a general strategy that would cover most cases.

A foliation field $S_{i}$ is first interpolated including all relevant data $\left(\mathrm{S}_{i}^{\dagger}, \nabla \mathrm{S}_{i}^{\dagger}, \mathrm{L}_{i}^{\dagger}\right)$. If a folding event that would affect $\mathrm{S}_{i}$ is defined, i.e. $\mathrm{F}_{i+1}$, we use $\mathcal{F}_{i+1}$ as an additional constraint. $\mathrm{S}_{i}$ is taken as the $z$ coordinate of the fold frame. The coordinates $y$ is then interpolated with the constraints for $y$ to be orthogonal to $z$, and $\mathrm{e}_{\mathrm{y}}$ to align at best on $\mathrm{L}_{i}^{\dagger}$. The coordinate $x$ is finally interpolated orthogonal to both $y$ and $z$.

\section{Fold rotation angles interpolation}

The fold plunge and limb rotation angles, $\alpha_{P}$ and $\alpha_{L}$, are defined as functions of the local fold coordinates. They can be interpolated from observed foliation and lineation data, and stored as scalar fields. When a particular fold model is considered, it becomes possible to express $\alpha_{P}$ and $\alpha_{L}$ with an analytic function of the fold coordinates (e.g. Section 3.3).

Ideally, analytic fold profiles should be fitted to data or used as a basis for data interpolation. Typical parameters for analytic fold profiles would be the fold wavelength $\lambda$, a range of fold rotation angle $\left[\alpha_{\text {Lmin }}, \alpha_{\text {Lmax }}\right]$, a hinge shape factor $p$. This modeling process should also consider that the values of $\alpha_{P}$ and $\alpha_{L}$ might be affected by overprinting folding event, for example by superimposing different analytic fold profiles. Combination of profiles is also a way to represent parasitic folds.

\section{Inferring deformed foliation orientation}

At any location $v$, the orientation of the fold axis $\mathrm{L}_{i}$ and deformed foliation $\nabla S_{i-1}$ are defined with respect to the local fold 


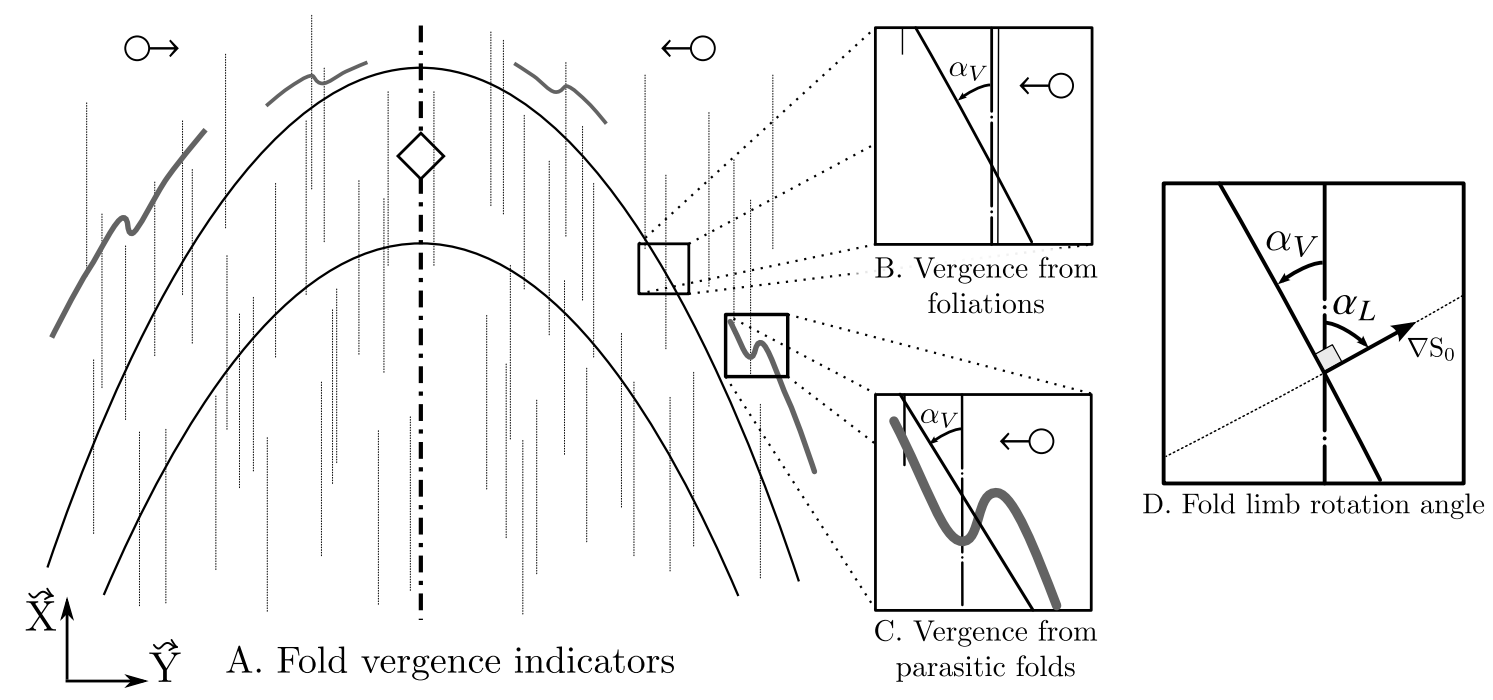

Figure 3 Fold limb rotation and vergence. A: Schematic of an antiform in cross-section with axial foliation and parasitic folds. Vergence symbols $\left(\mathrm{O} \rightarrow\right.$ ) represent the direction towards the next antiform in each limb of the fold. Vergence angle is computed either: (B) from an intersection of $\mathrm{S}_{1}$ and $\mathrm{S}_{0}$ foliations, or $(\mathrm{C})$ from the asymmetry of parasitic folds. D: Definition of fold limb rotation angle $\left(\alpha_{L}\right)$ with respect to vergence angle $\left(\alpha_{V}\right)$.

frame direction vectors $\left(e_{x}, e_{y}, e_{z}\right)$ with the following two rotations (Fig. 2C):

- Fold axis rotation $\mathrm{R}_{1}$ : rotates the whole frame around $\mathrm{e}_{\mathrm{z}}$ by a fold axis rotation angle $\alpha_{P}$, yielding:

$$
\mathrm{L}_{i}=\mathrm{R}_{1} \cdot \mathrm{e}_{\mathrm{y}}
$$

- Fold limb rotation $\mathrm{R}_{2}$ : rotates the whole frame around $\mathrm{L}_{i}$ by a fold limb rotation angle $\alpha_{L}$ (Fig. 3D), yielding:

$$
\nabla \mathrm{S}_{i-1}=\mathrm{R}_{2} \cdot \mathrm{R}_{1} \cdot \mathrm{e}_{\mathrm{z}}=\mathrm{R} \cdot \mathrm{e}_{\mathrm{z}}
$$

For cylindrical folds, $\mathrm{L}_{i}$ is constant in space, and can be represented by a global fold axis vector or rotation angle.

\section{Deformed foliation interpolation}

The final stage of the fold interpolator algorithm consists in interpolating $S_{i-1}$, while taking $S_{i-1}^{\dagger}$ and inferred $\nabla S_{i-1}$ into account. This is achieved by implementing fold related constraints in classical interpolation schemes [Frank et al., 2007, Hillier et al., 2014, Lajaunie et al., 1997]. Fold constraints control the orientation of $\nabla S_{i-1}$ with respect to fold axis, axial surface and fold limb directions. They also specify how $\nabla S_{i-1}$ must vary in space. As an example, Section 4 derives these constraints for discrete implicit schemes.

\section{Backward modeling of successive fold events}

Understanding the relationship between successive folding events provides a guideline to unravel poly-deformed geometry. The latest deformation event is modeled first, assuming that its associated foliation field $S_{n}$ should not have been affected by any later deformation and should then be relatively consistent and smooth through the studied area. This assumption makes it relevant to interpolate $S_{n}$ with classical interpolation tools [Frank et al., 2007, Hillier et al., 2014, Lajaunie et al., 1997]. Once the foliation field $\mathrm{S}_{n}$ is built, it is combined with some user-defined fold parameters to build a complete description of the folding event (Section 3.3). $\mathcal{F}_{n}$ is then applied to model $S_{n-1}$. This process is progressively repeated to model the geometry of older features until the bedding is finally generated (Fig. 4).

\section{Simplified fold interpolator for similar folds}

Dip isogons [Ramsay and Huber, 1987] correspond to lines of equal $\alpha_{L}$. For similar folds, the dip isogons are parallel to the axial surfaces. Therefore, $\alpha_{L}$ is constant for each iso-surface of $z_{i}$ and can be expressed as a function of $z$ only. This allows simplifications of the fold frame. Typically, $x$ does not bring any information and is not explicitly represented. Instead of using Eq.(1), $\mathrm{e}_{\mathrm{x}}$ is expressed as a cross product of $\mathrm{e}_{\mathrm{y}}$ and $\mathrm{e}_{\mathrm{z}}$ :

$$
\mathrm{e}_{\mathrm{x}}=\mathrm{e}_{\mathrm{z}} \times \mathrm{e}_{\mathrm{y}}
$$

We propose the following periodic function $\widetilde{\alpha_{L}}(z)$ as an example of possible parameterization of $\alpha_{L}, \lambda$ being the wavelength of the fold with respect to $z,|\cdot|$ the absolute value and $\langle\cdot\rangle$ the fractional part operator:

$$
\widetilde{\alpha_{L}}(z)=4\left|\frac{1}{2}-\left\langle\frac{z}{\lambda}-\frac{1}{4}\right\rangle\right|-1
$$

The shape of the fold hinge is another important characteristic for describing the geometry of a fold [Jessell et al., 2014]. It is represented by the fold hinge shape parameter $p$ (Fig. 5). For a same inter-limb angle, the curvature of the fold may be concentrated close to the hinge ( $p \gg 1$ ), evenly distributed between the hinge and the limb $(p=1)$, or spread towards the limbs $(p<1)$. This is implemented with the following equation, where $\alpha_{L \max }$ is the fold limb rotation angle at the inflexion point of the limb:

$$
\widehat{\alpha_{L}}(z)=\alpha_{L \max } \operatorname{Sign}\left(\widetilde{\alpha_{L}}(z)\right) \sqrt[p]{\left|\widetilde{\alpha_{L}}(z)\right|}
$$

\section{Structural FOLd CONSTRAintS FOR Discrete IMPLicit SCHEME}

In this section, we use our parameterization of fold structures to derive constraints that can be used in the framework of discrete implicit modeling.

\section{Discrete implicit approach}

A discrete implicit approach represents geological surfaces as a piecewise linear scalar field $\varphi$, which is defined by a discrete volumetric mesh [Caumon et al., 2013, Frank et al., 2007, Mallet, 


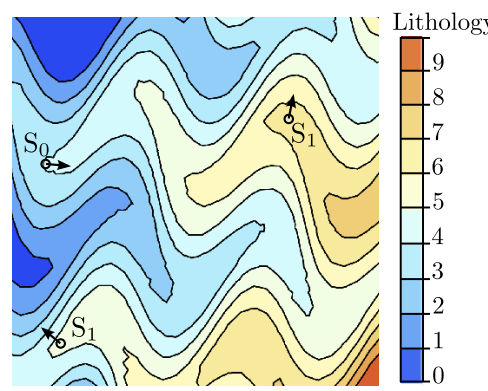

A. Complex fold interference pattern

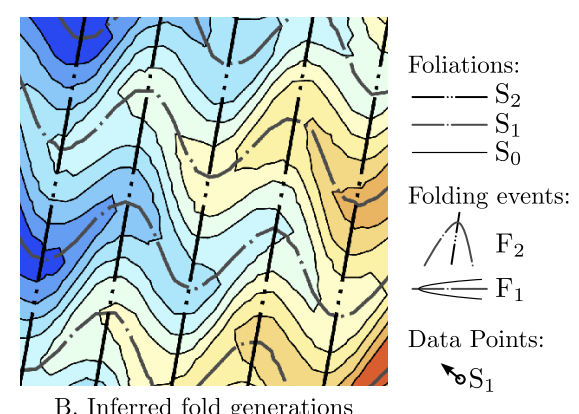

B. Inferred fold generations
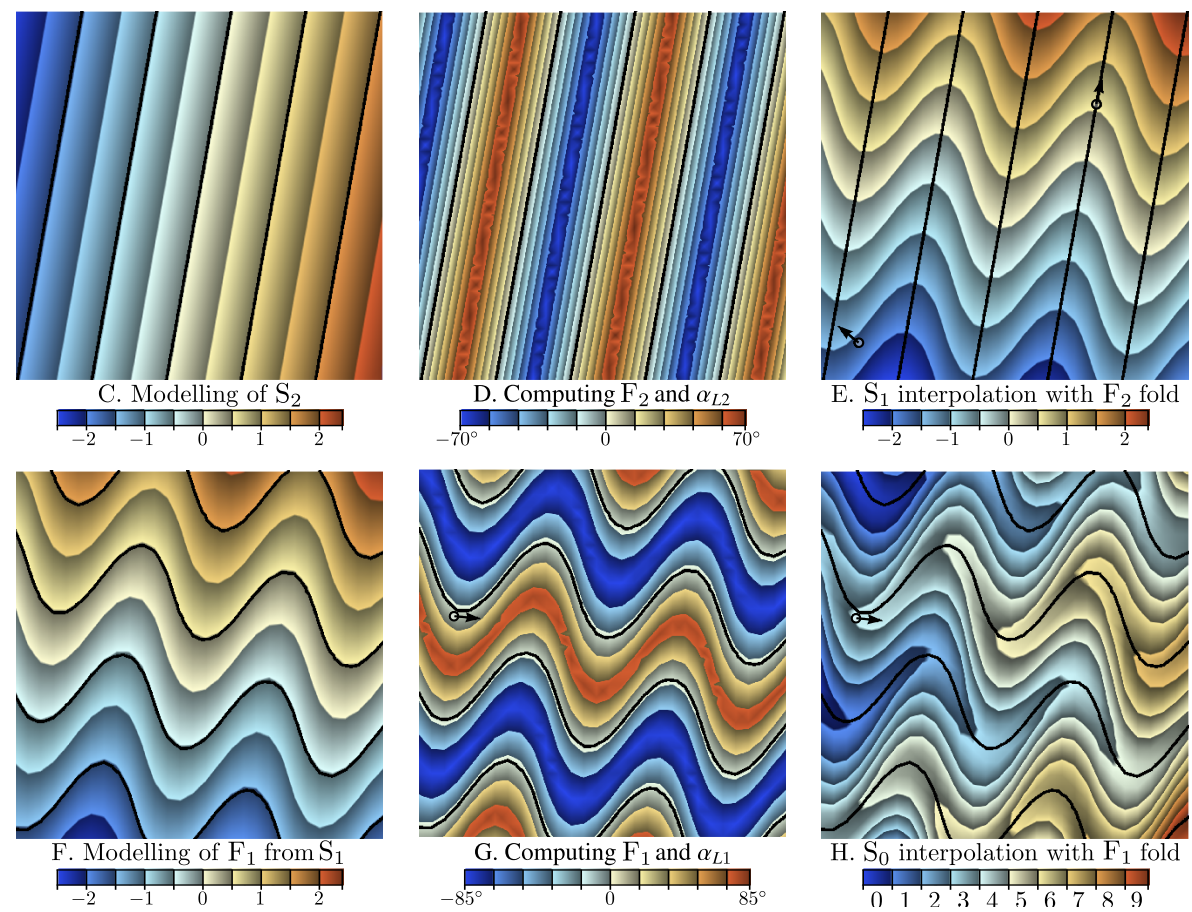

Figure 4 Iterative fold modeling process for a type-3 interference pattern [Ramsay and Huber, 1987]. A: Complex geometry of $\mathrm{S}_{0}$, modeled with a few data points $\left(S_{0}\right.$ and $\left.S_{1}\right)$. B: Structural interpretation, basis for the modeling showing the overprinting of two folding events. C: $S_{2}$ modeled from a general trend with a classical interpolation process and definition of $\mathrm{F}_{2}$ axial surfaces (black lines) as isosurfaces of $\mathrm{S}_{2}$ (imposing a wavelength of 2). D: fold rotation angle $\alpha_{L 2}$ modeled as a periodic function of $S_{2}$ with $\alpha_{L 2 \max }$ of $70^{\circ}$. E: $S_{1}$ interpolation based on $S_{1}^{\dagger}$ and $\mathcal{F}_{2}$. F: Definition of $F_{1}$ axial surfaces (black lines) from $\mathrm{S}_{1}$. G: fold rotation angle $\alpha_{L 1}$ modeled as a periodic function of $\mathrm{S}_{1}$ with $\alpha_{L 1 \max }$ of $85^{\circ}$. H: $\mathrm{S}_{0}$ interpolation based on $\mathrm{S}_{0}^{\dagger}$ and $\mathcal{F}_{1}$. 


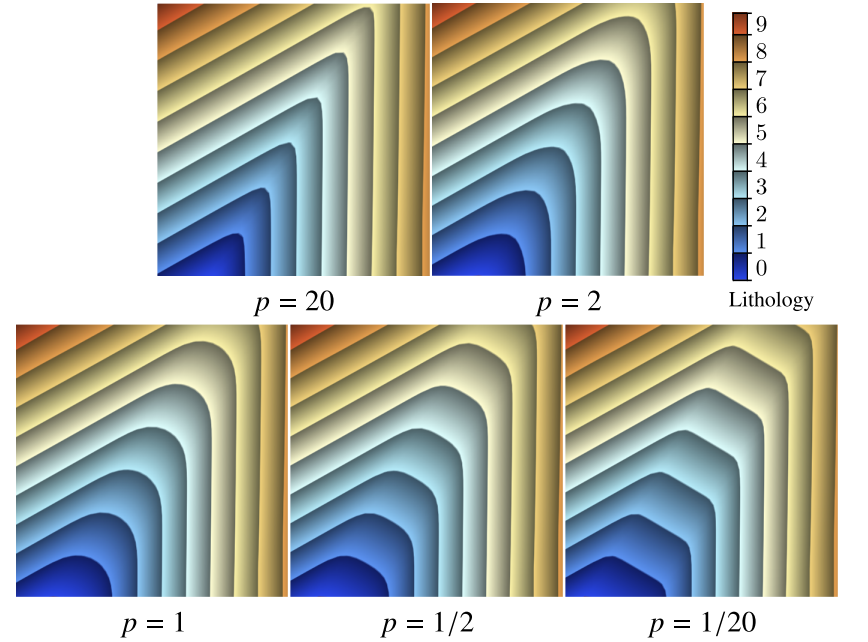

Figure 5 Effect of the fold hinge shape parameter $p$ on the shape of the folds. The figure shows an antiform with an $\alpha_{L \max }$ of $60^{\circ}$ and an axial surface dipping $30^{\circ}$ to the left.

2002, Moyen et al., 2004]. The scalar field is linearly interpolated from the nodal values $\varphi_{c}$ of each mesh element. The gradient of the scalar field $\nabla \varphi$ is constant in each element. Within tetrahedral elements, $\varphi$ and $\nabla \varphi$ are defined as functions of Cartesian coordinates, $\bar{x}, \bar{y}$, and $\bar{z}$, by two matrices $\mathbf{M}$ and $\mathbf{T}$, which depend on the geometry of the tetrahedron $(\mathrm{A})$ :

$$
\begin{aligned}
\varphi(\bar{x}, \bar{y}, \bar{z}) & =[1, \bar{x}, \bar{y}, \bar{z}] \cdot \mathbf{M} \cdot \varphi_{c} \\
\nabla \varphi(\bar{x}, \bar{y}, \bar{z}) & =\mathbf{T} \cdot \varphi_{c}
\end{aligned}
$$

The interpolation process finds optimal nodal values with respect to two conditions:

- Data boundary conditions: each observation of either the value of the scalar field or its gradient generates new linear equations by applying Eq.(8) and (9).

- A regularization term: it enforces the interpolation by smoothing the scalar field between the data boundary conditions. This is implemented by the so-called constant gradient constraint or roughness, which minimizes the gradient variation between neighbor elements [Frank et al., 2007].

These different constraints generate a system of linear equations, which is solved with a Least Squares approach yielding the corner values $\varphi_{c}$ as a solution [Frank et al., 2007].

The constant gradient constraint tends to progressively attenuate the orientation variations away from data. This has two consequences on the interpolation:

- Limiting the development of folds: this is because folds are actually introducing orientation variations, which should be used and propagated by the interpolator. In contrast, they tend to be erased by the constant gradient constraint.

- Promoting parallel fold shape: they are the type of fold that best spreads the orientation variations, yielding the lowest possible curvature. Therefore parallel folds are promoted by constant gradient constraint.

These observations call for the development of another type of regularization term to complement the capabilities of the constant gradient constraint.

\section{Structural fold constraints}

In addition to the above classical constraints, we propose a series of fold related constraints. Each constraint is defined with respect to the local fold frame direction vectors $\left(\mathrm{e}_{\mathrm{x}}, \mathrm{e}_{\mathrm{y}}, \mathrm{e}_{\mathrm{z}}\right)$ and fold rotation angles $\left(\alpha_{P}, \alpha_{L}\right)$.

\section{Gradient orientation constraints}

The orientation of $\nabla \varphi$ has to honor two constraints:

- Fold axis constraint: by definition, $\nabla \varphi$ is orthogonal to the fold axis $\mathrm{L}_{i}$ :

$$
\mathrm{L}_{i}^{t} \cdot \mathbf{T} \cdot \varphi_{c}=0
$$

- Fold limb rotation constraint: the fold rotation R (Eq. 4) constrains the orientation of $\nabla \varphi$ along the axial surface and in the limbs of the fold. This is added to the system in the form of:

$$
\mathrm{e}_{\mathrm{z}}{ }^{t} \cdot \mathrm{R}^{t} \cdot \mathbf{T} \cdot \varphi_{c}=0
$$

\section{Gradient norm and variation constraints}

We propose to use the local fold frame direction vectors $\left(\mathrm{e}_{\mathrm{z}}, \mathrm{e}_{\mathrm{x}}, \mathrm{e}_{\mathrm{y}}\right)$ for controlling which component of $\nabla \varphi$ may vary. These equations consider two adjacent tetrahedra, whose variables are respectively indexed 0 and ${ }_{1}$ :

$$
\begin{aligned}
& \mathrm{e}_{\mathrm{x} 0}{ }^{t} \cdot \mathrm{R}_{0}{ }^{t} \cdot \mathbf{T}_{0} \cdot \varphi_{c 0}-\mathrm{e}_{\mathrm{x} 1}{ }^{t} \cdot \mathrm{R}_{1}{ }^{t} \cdot \mathbf{T}_{1} \cdot \varphi_{c 1}=0 \quad \text { (parallel) } \\
& \mathrm{e}_{\mathrm{x} 0}{ }^{t} \cdot \mathbf{T}_{0} \cdot \varphi_{c 0}-\quad \mathrm{e}_{\mathrm{x} 1}{ }^{t} \cdot \mathbf{T}_{1} \cdot \varphi_{c 1}=0 \quad \text { (similar) }
\end{aligned}
$$

When considering parallel folds, the variation of thickness has to be minimized in the direction orthogonal to the folded foliation, i.e. the projection of $\nabla \varphi$ onto R $\cdot e_{x}$ should be constant (Eq. 12). For similar folds, only the apparent thickness in the direction $\mathrm{e}_{\mathrm{x}}$ is preserved.

A constraint for controlling the norm of the gradient $\|\nabla \varphi\|$ is also introduced. This may help to improve the quality of interpolated $\varphi$ when the fold frame is particularly curved, for example when refolding occurs.

$$
\begin{aligned}
\mathrm{e}_{\mathrm{x}}{ }^{t} \cdot \mathrm{R}^{t} \cdot \mathbf{T} \cdot \varphi_{c} & =1 / h_{p} & & \text { (parallel fold) } \\
\mathrm{e}_{\mathrm{x}}{ }^{t} \cdot \mathbf{T} \cdot \varphi_{c} & =1 / h_{s} & & \text { (similar fold) }
\end{aligned}
$$

$h_{p}$ and $h_{s}$ denote the local expected thickness of a unit layer for parallel fold and similar fold respectively.

\section{SyNTHETIC EXAMPLES OF FOLd INTERPOLATION}

Three synthetic cases are presented. The first example illustrates the process of modeling successive fold events. The second example demonstrates the possibility to fill a gap of information in a fold series and interpolate structural information. The last example simulates the process of creating a three-dimensional model of refolded layers from field observations.

\section{Modeling fold interference}

Figure 4 shows a cross-section where an upright fold $F_{2}$ overprints a recumbent fold $F_{1}$. This represents a type- 3 interference pattern as described by Ramsay and Huber [1987].

This complex structure is obtained by progressively modeling the effect of each fold event, starting with $\mathrm{F}_{2} . \mathrm{S}_{2}$ is modeled with 
a constant orientation through the model. Eq. (7) is then applied to compute $\alpha_{L 2}$ as a function of $s_{2}$, with $\lambda$ equals 2 and $\alpha_{L 2 m a x}$ set at $70^{\circ}$, which generates relatively open to tight folds. $\mathcal{F}_{2}$ is then used to interpolate $S_{1}$. The process is repeated for modeling $\mathrm{S}_{0}$ with respect to $\mathrm{F}_{1}$, using a $\alpha_{L 1 \mathrm{max}}$ of $85^{\circ}$ and a wavelength of 2.

\section{Structurally-controlled fold series interpolation}

Figure 6 illustrates the interpolation of an irregularly sampled fold series. This example considers two outcrops with dense data sampling separated by an area lacking observations. Classical interpolation smooths the stratigraphy and fills the gap with a very large synform (Fig. 6A), which is inconsistent with the regular wavelength observed in the dataset. With our approach, this dataset may be interpreted as a consistent series of folds. The fold limb rotation angle is computed following Eq.(7). Different simulations are produced with varying wavelength $\lambda$, inflexion point angle $\alpha_{L \max }$ and hinge shape parameter $p$ (Fig. 6B-E). This illustrates how different fold geometries honoring observation data can be simulated using our parameterization.

\section{Complex synthetic case study}

Our last experiment simulates the construction of a complex structural model from field data. We use a synthetic example as it makes it possible to work in a controlled environment and to compare final results with a reference model.

\section{Synthetic reference model and data extraction}

The reference model has been created with a history-based approach [Jessell and Valenta, 1996]. It represents a series of 11 stratigraphic layers, with varying thickness as shown by the stratigraphic column (Fig. 9A). The model is 1 by 1 kilometers large and 500 meters high. A topography representing a valley cutting through a plateau has been simulated, with elevations varying between 20 and 200 meters (Fig. 7A). Two folding events are considered:

- $\mathrm{F}_{1}$ : large scale reclined folds (wavelength: $608 \mathrm{~m}$, amplitude: $435 \mathrm{~m}$, fold axis: $\left.\mathrm{N} 000 \mathrm{E} / 45^{\circ}\right)$.

- $\mathrm{F}_{2}$ : upright open folds (wavelength: $400 \mathrm{~m}$, amplitude: $30 \mathrm{~m}$, fold axis: parallel to $\mathrm{L}_{1}$ ).

The two folding events overprint in a type- 3 interference pattern [Ramsay and Huber, 1987].

Three outcropping regions have been delineated covering $30 \%$ of the modeled area. Data have been extracted from this reference model by picking the orientation of corresponding surfaces or by intersecting them with the topographic surface (Fig. 7). Four kinds of data are generated:

- Contacts lines between stratigraphic layers.

- Form lines of $\mathrm{S}_{0}, \mathrm{~S}_{1}$ and $\mathrm{S}_{2}$.

- Orientation of $S_{0}, S_{1}$ and $S_{2}$.

- Intersection lineations for $\mathrm{F}_{1}$ and $\mathrm{F}_{2}$.

The chosen sampling of orientation data produces values that are representative of a certain radius around the picked point and has inherent inaccuracy in the way it locates the measurements. This emulates the way orientation data are collected in the field, with location uncertainty and orientation upscaling. This process ensures that generated data carry the same kind of uncertainty as those collected in the field.

\section{Sequential fold modeling process}

We apply the modeling process presented in Section 3. The following features are successively modeled:

- $\mathrm{S}_{2}$ (Fig. 8A): interpolated from $\mathrm{S}_{2}$ orientation measurements and form lines. One of the orientation control points is attributed a value of 0 and a gradient norm of 1 to make the interpolation solution unique.

- $\alpha_{L 2}$ (Fig. 8B): modeled from the geometrical characteristics of $F_{2}$ with respect to $S_{2}$ with the following parameters: $\left[\alpha_{\text {Lmin }}, \alpha_{\text {Lmax }}\right]=[-25,+25], \lambda=390, p=1$.

- $\mathrm{S}_{1}$ (Fig. 8C): interpolated from $\mathrm{S}_{1}$ orientation measurements and form lines with constraints derived from $\mathrm{F}_{2}$. Fold constraints that are used correspond to a fold axis constraint Eq.(10), a fold limb rotation constraint Eq.(11) and similar fold regularization Eq.(13). Two additional value data points are introduced in the northern and southern borders of the model to help the interpolated values to stretch in the whole model and limit problems of gradient norm diffusion due to the limited number of value constraints [Laurent, 2016]. In addition, a similar fold gradient norm constraint Eq.(15) appears to be necessary to obtain good results.

- $\alpha_{L 1}$ (Fig. 8D): derived from $\mathrm{S}_{0}$ measurement and interpolated $S_{1}$, similarly as in stage 2 , with the following parameters: $\left[\alpha_{\text {Lmin }}, \alpha_{\text {Lmax }}\right]=[-80,+80], \lambda=100, p=5$.

- $\mathrm{S}_{0}$ (Fig. 9C): finally interpolated from $\mathrm{S}_{0}$ measurements and form lines, with constraints derived from $\mathrm{F}_{1}$.

\section{Structural analysis of resulting models}

The quality of the result is qualitatively evaluated by comparing with the reference model and the result obtained with constraints used in classical interpolator (bedding contours and orientations, and a fold axis direction) (Fig. 9). With this example, classical interpolation honors bedding information and roughly captures the central $F_{1}$ fold. But several aspects appear to be very different from the reference model:

- The style of the modeled fold is not correct: the fold obtained corresponds to a parallel fold, and shows no hinge thickening apart from where it is directly constrained by the data, whereas $F_{1}$ are similar folds with thickened hinges and attenuated limbs in the reference model.

- $\mathrm{F}_{2}$ are not visible which causes the limbs of the $\mathrm{F}_{1}$ fold to be much smoother than in the reference model.

- The style of $F_{1}$ hinges is very different from the reference model. They are wide and open in the interpolated model, whereas they are narrow and acute in the reference one.

- There is only one axial surface of $F_{1}$ causing the limbs to continue straight without folding again. This results in very different stratigraphy in the South-West and NorthWest part of the model, where the stratigraphy is not repeated as in the reference model.

The model obtained with the proposed method (Fig. 9C) appears to be much closer to the reference model. Overall, the obtained geometries are more satisfactory when comparing the structural elements of the folds. They honor the principal characteristics of the reference model:

- Several $F_{1}$ folds are visible, which makes the resulting stratigraphy much closer from the reference model in the South-West and North-West parts.

- $F_{1}$ are close to similar folds, showing hinge thickening, limb attenuation and tight hinges. 


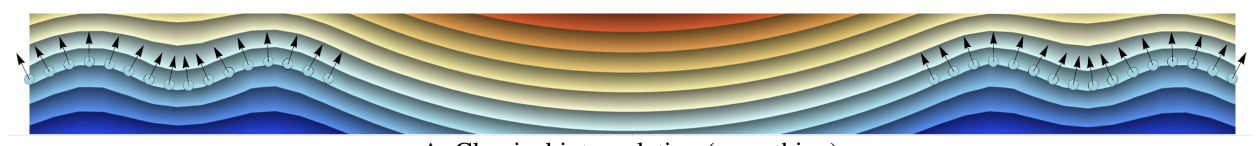

A. Classical interpolation (smoothing)

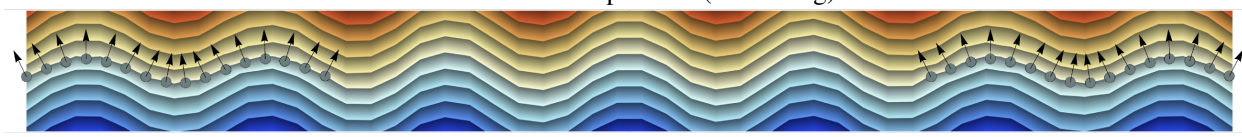

B. Fold interpolation $\left(\lambda: 6, \alpha_{L \max }: 45^{\circ}, p: 1\right)$

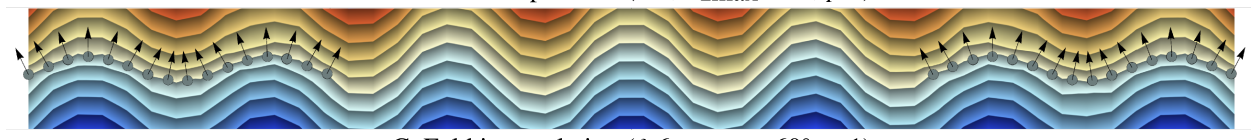

C. Fold interpolation $\left(\lambda: 6, \alpha_{L \max }: 60^{\circ}, p: 1\right)$

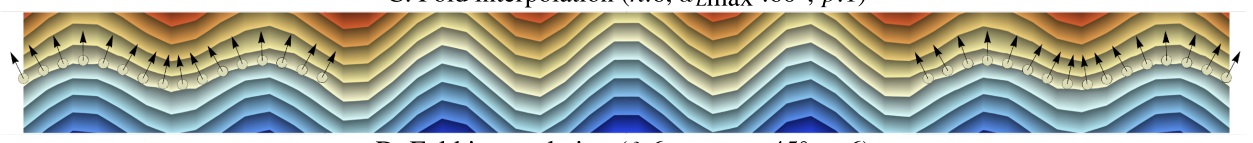

D. Fold interpolation $\left(\lambda: 6, \alpha_{L \max }: 45^{\circ}, p: 6\right)$

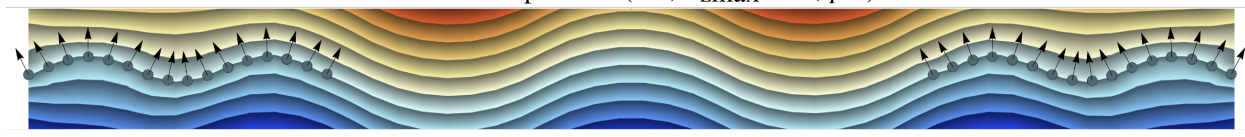

E. Fold interpolation $\left(\lambda: 12, \alpha_{L \max }: 30^{\circ}, p: 1\right)$

Figure 6 Comparison between classical interpolation and fold interpolation. The same data points (circles and arrows) are considered in each interpolation. There is a gap in available data, where the interpolation behavior of each interpolator is observed. A: classical interpolation obtained with a constant gradient regularization term. B-E: proposed method of fold interpolation with different fold parameter values.

- $F_{2}$ refolding $F_{1}$ are visible, with undulating stratigraphy in $\mathrm{F}_{1}$ limbs.

Some differences can still be observed. Mainly, the southern and northern $F_{1}$ hinges are slightly shifted as compared to the reference model, which causes the stratigraphy to be different in this regions. This is interpreted as an effect of small variations of $S_{1}$ gradient norm on the southern and northern borders of the model, which are related to difficulties in interpolating $S_{1}$. However, these disparities are located in areas that are not controlled by any data, and thus seem very acceptable.

\section{Quantitative analysis of resulting models}

The quality of the result obtained with a classical interpolation and the proposed fold interpolation method are quantified by measuring the difference in stratigraphic value and orientation with respect to the reference model (Fig. 10).

Both interpolation methods generate relatively low errors of stratigraphic value and orientation in the regions with high data density (i.e. outcrops). For the model interpolated with the classical method, the error rapidly increases when going away from the well constrained areas (Fig. 10AC).

The proposed method interpolates stratigraphic values that are closer to the reference model (Fig. 10B). Important variations are still observed, in particular in the NW and SE corners of the model, which is mainly due to (1) a limited conditioning of this stratigraphic areas, and (2) problems of diffusion when interpolating $S_{1}$ (Section 5.3.2). The differences of orientation are concentrated in the $\mathrm{F}_{1}$ hinges. The location and the shape of the hinges are not correctly accounted for (Fig. 10D).

\section{Discussion ANd perspectives}

Case studies presented in this paper demonstrate how our approach improves the capability of structural interpolator to generate realistic and structurally-controlled stratigraphy, that honors all available structural constraints. Jessell et al. [2014] highlight two limitations of current implicit modeling schemes: (1) they are incapable of interpolating or extrapolating a fold series with a continuous structural style (Fig. 6A); (2) the shape of fold hinges they produce is not controlled and may yield inconsistent geometries. These two caveats are addressed by our approach. We are able to interpolate and extrapolate while honoring assumptions about the continuity of the structural style (Fig. 6B-E), and about the shape of the fold hinges (Fig. 5).

This process needs a practical way to infer fold parameters from field observations. Here, they have been manually determined by comparing the inferred orientation of interpolated foliations to the dataset. This trial and error process was sufficient for proving the concept of our approach, but would be a limitation for complex applications. Early attempts have shown encouraging results in using statistical approaches to derive parameters such as wavelength and fold directions. Unfortunately, the difficulty of this task increases with the complexity of the folds and the number of folding events. We think the fold frame introduced in Section 2.3 provides an appropriate structure to carry out such statistical analysis, but this needs to be further developed in future work. Such a tool would have to consider the uncertainties that are related to the determination of fold parameters, for example by using a probabilistic approach. In this contribution, only the parameterization of fold rotation angle for similar folds has been presented. A general method to compute it for any type of fold also needs to be investigated.

There is still a gap between the requirements of the fold modeling process (Section 3 ) and the proposed fold constraints (Section 4.2). Here, we focused on the way a fold event would deform the axial surface of an earlier fold. The effect of $\mathcal{F}$ on fold axis and rotation angles also need to be better characterized.

The interpolation schemes that are used represent another point of discussion. The discrete implicit method is able to balance the contribution of each constraint when assembling its linear system. The result may be very sensitive to the relative weight of the different constraints. This is beneficial because it allows for the relative weights to be adapted to different structural styles and data confidence. Ideal relative weights may be difficult to 


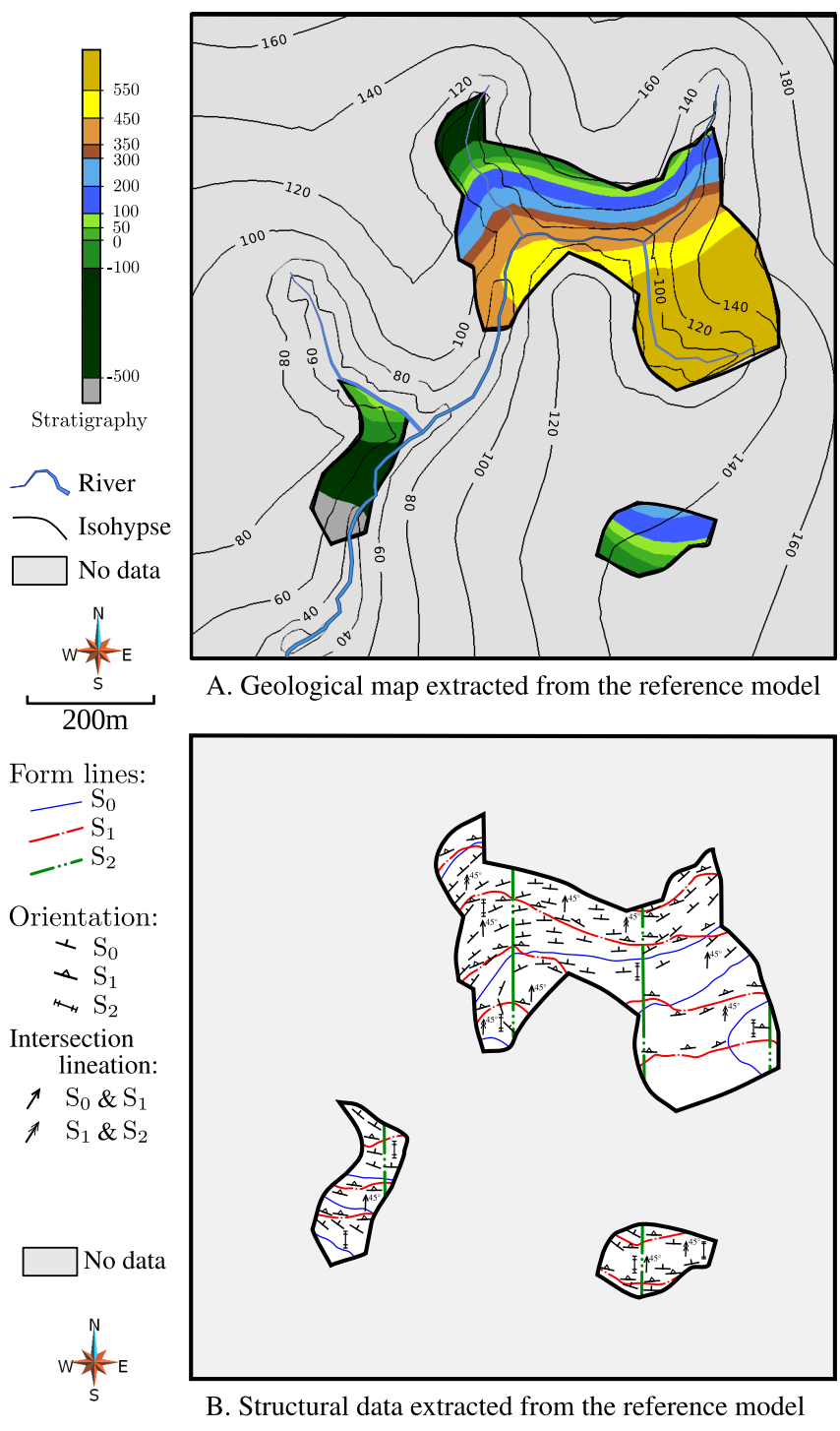

Figure 7 Synthetic data generated from the reference model used in this study (Fig. 9A). A: Stratigraphic column, topography and stratigraphic outcrop map. B: Structural data gathering foliation orientation measurements, form lines and intersection lineations. find and would depend on the quantity and quality of available data.

In the discrete implicit approach, the mesh plays an important role in terms of feature resolution and of computation time. Larger wavelength folds could probably be modeled using a coarser mesh than tighter folds. It would be interesting to adapt the mesh with respect to the modeled fold event. The modeled features are also more likely to present a high curvature close to the fold hinges than in the limb. The mesh could then be adapted to the position in the axial surface field of the current fold. Unfortunately, discrete linear approaches also suffer from limitations related to the underlying mesh as illustrated in Laurent [2016].

In this contribution, the fold axis direction is represented by an angle $\alpha_{P}$ of rotation of $\overrightarrow{\mathrm{Y}}$ axis. Alternatively, a 3D vector field interpolated from the fold axis orientation data could be used. This is not the approach we are promoting here as the process of interpolating a direction field needs to be further developed. The description we are using is however compatible with this representation of the fold axis field. The fold axis could also be represented as the gradient of a scalar field, but we advocate that this option would introduce undesired limitations because the curl of such a vector field would be 0 , which is not the case of typical fold axis direction field we would like to model.

\section{Conclusion}

Two principal contributions to geological modeling and structural geology are presented in this paper:

- A theoretical and numerical framework for modeling superimposed folding events.

- A series of constraints for discrete implicit modeling schemes dedicated to fold geometry modeling.

Further developments remain necessary to make this technique fully applicable in the context of a real case study. However, this paper represents a step towards a better integration of geological knowledge and structural parameters into the interpolation schemes. The complex synthetic case study presented in Section 5.3 proves this approach useful for building structural models from field data, but would now have to be tested on a real case study.

The main development perspectives of this method are the extension of the fold parameterization to other types of folds and the implementation of a robust and efficient method for deriving fold parameters from observation data. This would give the opportunity to develop new kinds of uncertainty studies. Existing literature focuses on the geological uncertainty related to measurement data [Lindsay et al., 2012, Wellmann and Regenauer-Lieb, 2012], which is investigated by perturbing the measurements within uncertainty ranges. Others studies have defined parametric objects to produce stochastic model of faults [Cherpeau et al., 2010a,b, 2012, Cherpeau and Caumon, 2015, Laurent et al., 2013]. With our approach, it also becomes possible to produce stochastic fold models by altering or randomly drawing the structural parameters of folds, which would give interesting insights into the contribution of geological structures to the global uncertainty. It would also give better guarantees that models generated during coupled geological and geophysical inversion are actually geologically likely, especially in the context of hard rock terranes.

\section{Acknowledgments}

This research was developed at Monash University and funded by Australian Research Council Discovery grant DP110102531 

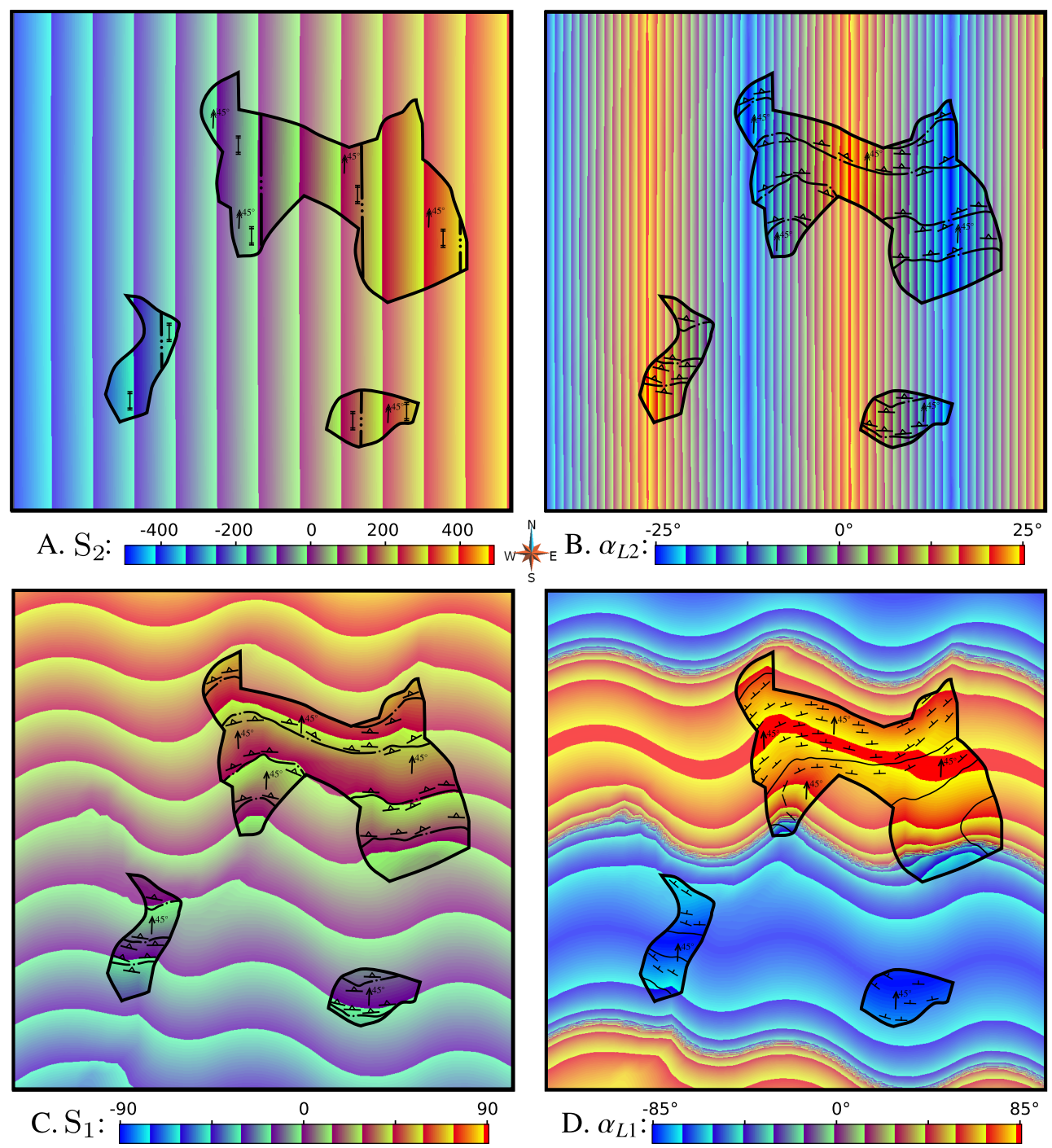

Figure 8 Successive stages of the proposed modeling process. Interpolated foliation fields and fold rotation angle are painted on the topographic surface, within and between the outcrop areas (thick lines): $\mathrm{S}_{2}(\mathrm{~A}), \alpha_{L 2}(\mathrm{~B}), \mathrm{S}_{1}(\mathrm{C}), \alpha_{L 1}$ (D). Visible sharp features of interpolated $\mathrm{S}_{1}$ and $\alpha_{L 1}$ are the effect of the topography. Relevant symbols from Fig. 7B are shown to represent the data used for each stage. 

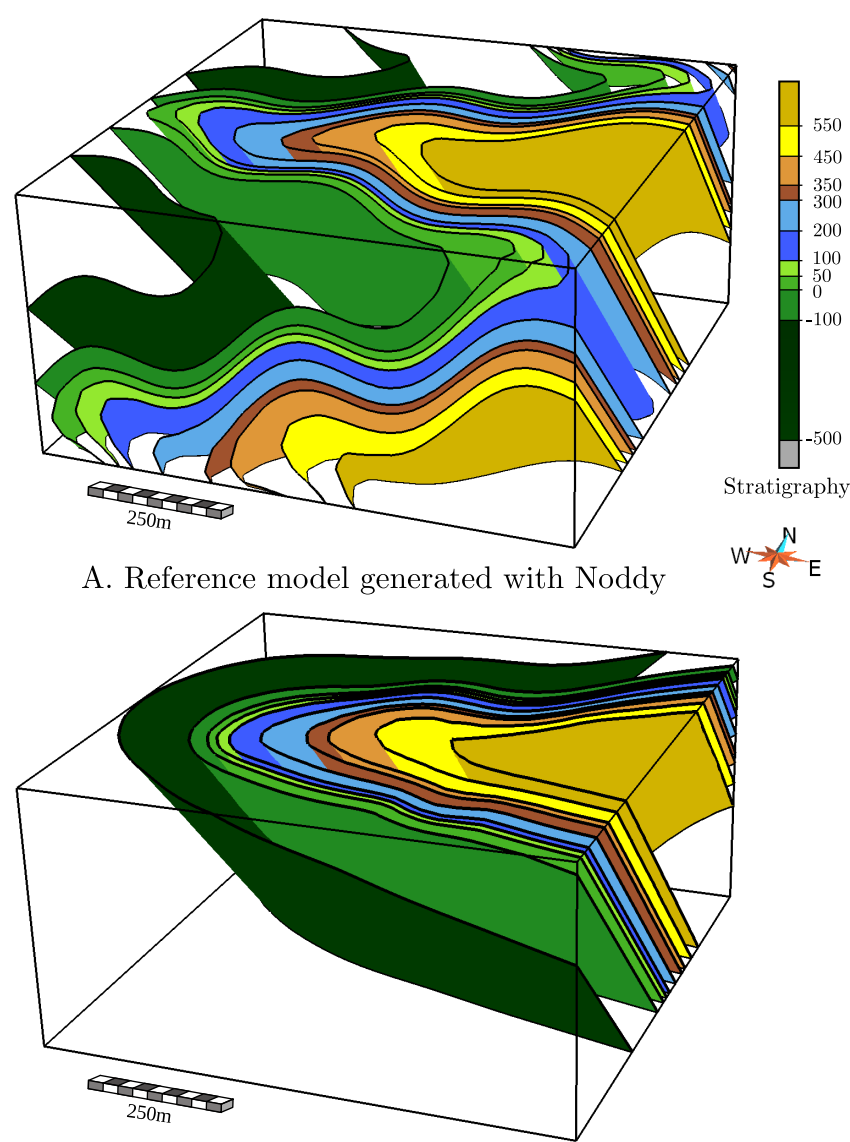

B. Model obtained with classical interpolation

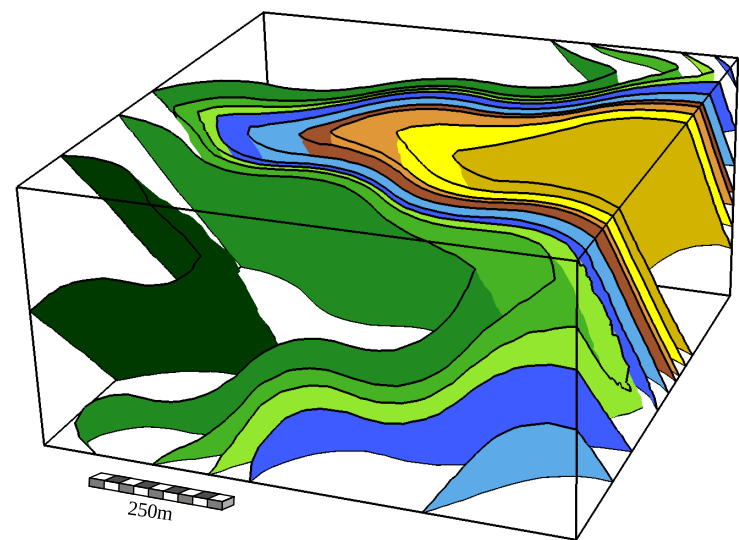

C. Model obtained with the proposed interpolation process

Figure 9 Complex synthetic case study. A: Reference model generated with a history-based approach [Jessell and Valenta, 1996]. B: Result of modeling with classical interpolation constraints (stratigraphy, bedding orientation and $\mathrm{F}_{1}$ fold axis). $\mathrm{C}$ : Result obtained with the proposed approach. and UWA linkage grant LP140100267. Part of this work was performed in the framework of the "Investissements d'avenir" Labex RESSOURCES21 (ANR-10-LABX-21) and of the RING project at Université de Lorraine. The authors are grateful to the Gocad Research Consortium managed by ASGA (Association Scientifique pour la Géologie et ses Applications, http://ring.georessources.univ-lorraine.fr/). We thank Paradigm for providing the GOCAD-SKUA software and API. The presented tools have been implemented in the StructuralFactory plugin for Gocad-Skua, developed by Dr. Gautier Laurent and Lachlan Grose, based on StructuralLab from the Gocad Research Consortium. Data and tools used in this this paper are available upon request to the corresponding author. We would like to thank Gabriel Courrioux and an anonymous reviewer for their very positive comments that helped improve this paper.

\section{References}

\section{References}

Bond, C. E., A. D. Gibbs, Z. K. Shipton, S. Jones, and G. B. Stracher (2007), What do you think this is? "Conceptual uncertainty" in geoscience interpretation, GSA today, 17(11), 4-10, doi:10.1130/GSAT01711A.1. (Cited page 1)

Bond, C. E. (2015), Uncertainty in structural interpretation: Lessons to be learnt, Journal of Structural Geology, 74, 185-200, doi:10.1016/j.jsg.2015.03.003. (Cited page 1)

Calgagno, P., J. P. Chilès, G. Courrioux, and A. Guillen (2008), Geological modelling from field data and geological knowledge Part I. Modelling method coupling 3D potential-field interpolation and geological rules, Physics of the Earth and Planetary Interiors, 171, 147-157. (Cited pages 1 and 2)

Caumon, G. (2010), Towards stochastic time-varying geological modeling, Mathematical Geosciences, 42(5), 555-569. (Cited page 1)

Caumon, G., P. Collon-Drouaillet, C. de Veslud, S. Viseur, and J. Sausse (2009), Surface-based 3D modeling of geological structures, Mathematical Geosciences, 41(8), 927-945. (Cited page 1)

Caumon, G., G. G. Gray, C. Antoine, and M.-O. Titeux (2013), 3D implicit stratigraphic model building from remote sensing data on tetrahedral meshes: theory and application to a regional model of La Popa Basin, NE Mexico, IEEE Transactions on Geoscience and Remote Sensing, 51(3), 1613-1621, doi:10.1109/TGRS.2012.2207727. (Cited pages 1, 2, and 5)

Cherpeau, N., G. Caumon, and B. Lévy (2010a), Stochastic simulations of fault networks in 3D structural modeling, Comptes Rendus Geosciences, 342(9), 687-694, doi:10.1016/j.crte.2010.04.008. (Cited pages 1 and 10)

Cherpeau, N., G. Caumon, and B. Lévy (2010b), Stochastic simulation of fault networks from 2D seismic lines, SEG Technical Program Expanded Abstracts, 29(1), 2366-2370, doi:10.1190/1.3513325. (Cited pages 1 and 10)

Cherpeau, N., G. Caumon, J. K. Caers, and B. Lévy (2012), Method for stochastic inverse modeling of fault geometry and connectivity using flow data, Mathematical Geosciences, 44(2), 147-168, doi:10.1007/s11004-012-9389-2. (Cited pages 1 and 10)

Cherpeau, N., and G. Caumon (2015), Stochastic structural modelling in sparse data situations, Petroleum Geosciences, 21(4), 233-247, doi:10.1144/ petgeo2013-030. (Cited pages 1 and 10)

Chilès, J.-P., C. Aug, A. Guillen, and T. Lees (2004), Modelling the geometry of geological units and its uncertainty in 3D from structural data: the potential-field method, in Proceedings of International Symposium on Orebody Modelling and Strategic Mine Planning, Perth, Australia, pp. 313-320. (Cited page 1)

Collon-Drouaillet, P., W. Steckiewicz-Laurent, J. Pellerin, G. Laurent, G. Caumon, G. Reichart, and L. Vaute (2015), 3D geomodelling combining implicit surfaces and Voronoi-based remeshing: A case study in the Lorraine Coal Basin (France), Computer $\mathcal{E}$ Geosciences, 77, 29-43, doi:10.1016/j.cageo. 2015.01.009. (Cited page 2)

Cowan, E. J., R. K. Beatson, H. J. Ross, W. R. Fright, T. J. McLennan, T. R Evans, J. C. Carr, R. G. Lane, D. V. Bright, A. J. Gillman, P. A. Oshust, and M. Titley (2003), Practical implicit geological modelling, in Fifth International Mining Geology Conference. Australian Institute of Mining and Metallurgy, Bendigo, Victoria, pp. 17-19. (Cited page 1)

Cox, S. F., V. J. Wall, M. A. Etheridge, and T. F. Potter (1991), Deformational and metamorphic processes in the formation of mesothermal vein-hosted gold 


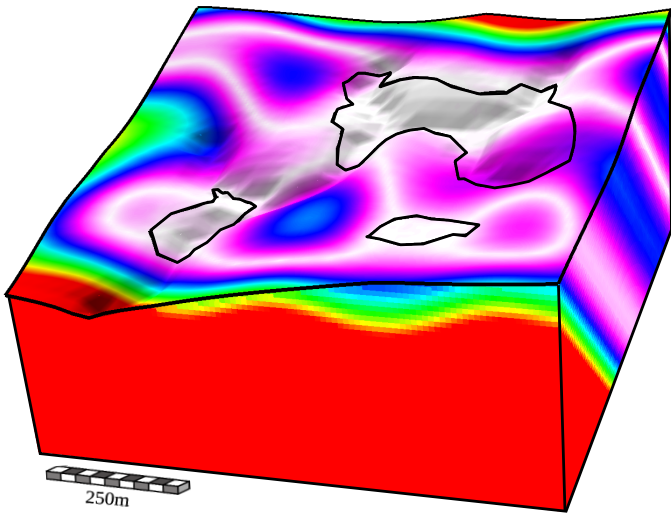

A. Stratigraphic difference classical interpolation

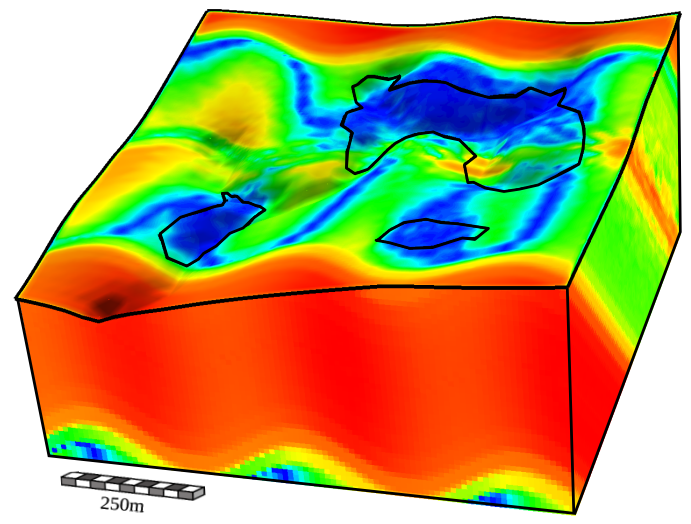

C. Orientation difference classical interpolation

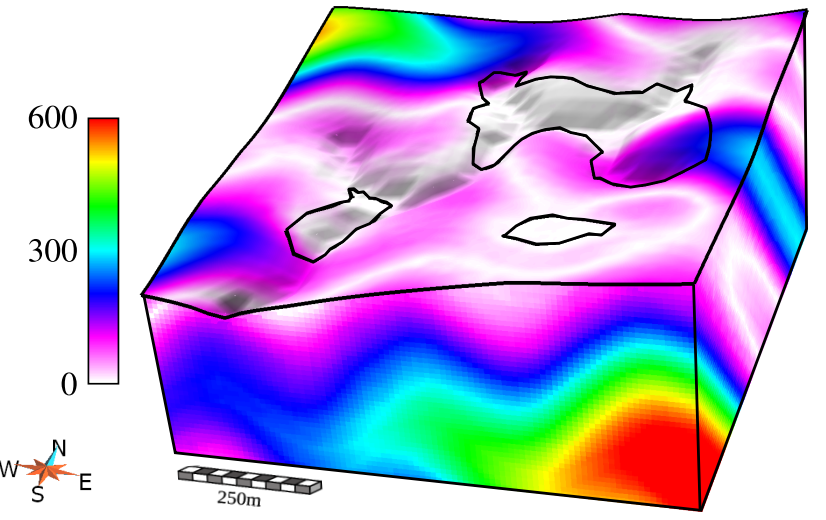

B. Stratigraphic difference: proposed interpolation

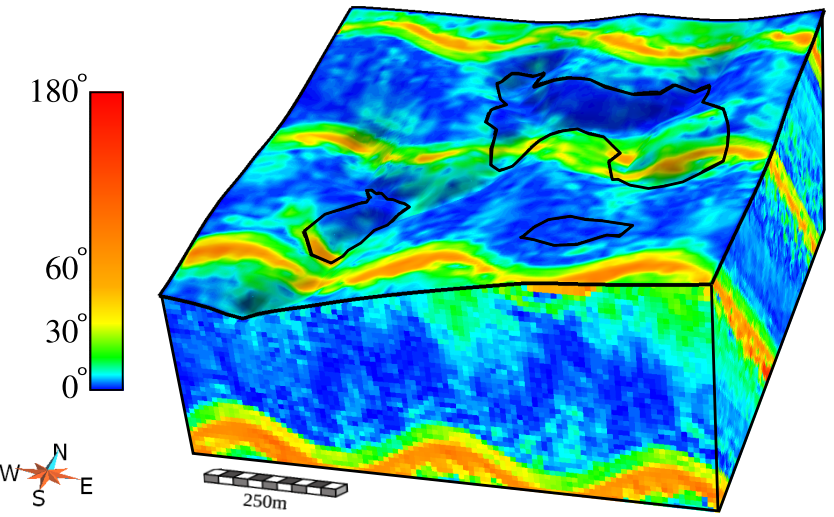

D. Orientation difference: proposed interpolation

Figure 10 Comparison of the results with the reference model: Absolute difference of stratigraphic value obtained with classical interpolation (A) and the proposed fold interpolation process (B) with respect to the reference model; Angle (degrees) between reference model stratigraphy orientation and orientation obtained with classical interpolation (C) and the proposed method (D). The top of the block model corresponds to the topographic surface, with a view of the outcrops (black contour). 
deposits - examples from the Lachlan Fold Belt in central Victoria, Australia Ore Geology Reviews, 6(5), 391-423, doi:10.1016/0169-1368(91)90038-9. (Cited page 1)

Forbes, C. J., P. G. Betts, and G. S. Lister (2004), Synchronous development of Type 2 and Type 3 fold interference patterns: evidence for recumbent sheath folds in the Allendale Area, Broken Hill, NSW, Australia, Journa of Structural Geology, 26(1), 113-126, doi:10.1016/S0191-8141(03)00074-9. (Cited page 1)

Frank, T., A. L. Tertois, and J. L. Mallet (2007), 3D-reconstruction of complex geological interfaces from irregularly distributed and noisy point data Computers $\mathcal{E}$ geosciences, 33(7), 932-943, doi:10.1016/j.cageo.2006.11.014. (Cited pages 1, 2, 5, 7, and 14)

Grasemann, B., G. Wiesmayr, E. Draganits, and F. Fusseis (2004), Classification of refold structures, The Journal of Geology, 112(1), 119-125, doi:10.1086/ 379696. (Cited pages 3 and 4)

Guillocheau, F., D. Rouby, C. Robin, C. Helm, N. Rolland, C. Le Carlier de Veslud, and J. Braun (2012), Quantification and causes of the terrigeneous sediment budget at the scale of a continental margin: a new method applied to the Namibia-South Africa margin, Basin research, 24, 3-30, doi:10.1111/j. 1365-2117.2011.00511.x. (Cited page 1)

Hillier, M. J., E. M. Schetselaar, E. A. de Kemp, and G. Perron (2014), ThreeDimensional Modelling of Geological Surfaces Using Generalized Interpolation with Radial Basis Functions, Mathematical Geosciences, 46(8), pp. 931953, doi:10.1007/s11004-014-9540-3. (Cited pages 1 and 5)

Hjelle, Ø., S. A. Petersen, and A. M. Bruaset (2013), A Numerical Framework for Modeling Folds in Structural Geology, Mathematical Geosciences, 45(3), 255-276. (Cited page 1)

Jessell, M. W., L. Aillères, E. D. Kemp, M. Lindsay, F. Wellmann, M. Hillier, G. Laurent, T. Carmichael, and R. Martin (2014), Next Generation Three-Dimensional Geologic Modeling and Inversion, in Society of Economic Geologists Special Publication 18, chap. 13, pp. 261-272. (Cited pages 1, 5, and 9)

Jessell, M. W., and R. K. Valenta (1996), Structural geophysics: integrated structural and geophysical modelling, Computer Methods in the Geosciences, 15, 303-324. (Cited pages 8 and 12)

Jessell, M. W., L. Aillères, and E. A. de Kemp (2010), Towards an integrated inversion of geoscientific data: What price of geology?, Tectonophysics, 490(34), 294-306. (Cited page 1)

Lajaunie, C., G. Courrioux, and L. Manuel (1997), Foliation fields and 3D cartography in geology: principles of a method based on potential interpolation, Mathematical Geology, 29(4), 571-584. (Cited pages 1 and 5)

Laurent, G., G. Caumon, A. Bouziat, and M. Jessell (2013), A parametric method to model $3 \mathrm{D}$ displacements around faults with volumetric vector fields, Tectonophysics, 590, 83-93, doi:10.1016/j.tecto.2013.01.015. (Cited pages 1, 2, and 10)

Laurent, G. (2016), Iterative thickness regularization of stratigraphic layers in discrete implicit modeling, Mathematical Geosciences, , -, doi:10.1007/ s11004-016-9637-y. (Cited pages 8 and 10)

Li, Y., D. Jia, M. Wang, J. H. Shaw, J. He, A. Lin, L. Xiong and G. Rao (2014), Structural geometry of the source region for the $2013 \mathrm{Mw}$ 6.6 Lushan earthquake: Implication for earthquake hazard assessment along the Longmen Shan, Earth and Planetary Science Letters, 390, 275-286, doi:10.1016/j.eps1 2014.01.018. (Cited page 1)

Lindsay, M. D., L. Aillères, M. W. Jessell, E. A. de Kemp, and P. G. Betts (2012), Locating and quantifying geological uncertainty in three-dimensional models: Analysis of the Gippsland Basin, southeastern Australia, Tectonophysics, 546, 10-27. (Cited pages 1 and 10)

Lisle, R. J., and N. C Toimil. (2007), Defining folds on three-dimensional surfaces, Geology, 35(6), 519-522, doi:10.1130/G23207A.1. (Cited page 1)

Mallet, J.-L. (1992), Discrete smooth interpolation in geometric modelling, Computer-Aided Design, 24(4), 178-191, doi:10.1016/0010-4485(92) 90054-E. (Cited page 1)

Mallet, J.-L. (2002), Geomodeling, Oxford University Press, New York, NY, USA. (Cited page 5)

Mallet, J.-L. (2004), Space-Time Mathematical Framework for Sedimentary Geology, Mathematical Geology, 36(1), 1-32. (Cited page 1)

Mallet, J.-L. (2014), Elements of mathematical sedimentary geology: The GeoChron model, EAGE Publications BV. (Cited pages 1 and 2)

Maxelon, M., P. Renard, G. Courrioux, M. Brändli, and N. Mancktelow (2009), A workflow to facilitate three-dimensional geometrical modelling of complex poly-deformed geological units, Computers $\mathcal{E}$ Geosciences, 35(3), 644-658. (Cited pages 1 and 4)

Moyen, R., J.-L. Mallet, T. Frank, B. Leflon, and J.-J. Royer (2004), 3DParameterization of the 3D geological space - The GeoChron model, in Proc. 9th European Conference on the Mathematics of Oil Recovery, EAGE. (Cited page 5)
Mueller, A. G., L. B. Harris, and A. Lungan (1988), Structural control of greenstone-hosted Gold mineralization by transcurrent shearing: A new interpretation of the Kalgoorlie mining district, Western Australia, Ore Geology Reviews, 3(4), 359-387, doi:10.1016/0169-1368(88)90027-3. (Cited page 1)

Mynatt, I., S. Bergbauer, and D. D. Pollard (2007), Using differential geometry to describe 3-D folds, Journal of Structural Geology, 29(7), 1256-1266, doi: 10.1016/j.jsg.2007.02.006. (Cited page 1)

Perrin, M., P. H. Oltra, and S. Coquillart (1988), Progress in the study and modelling of similar fold interferences, Journal of Structural Geology, 10(6), 593-605. (Cited page 4)

Ramsay, J. G. (1962), Interference Patterns Produced by the Superposition of Folds of Similar Type, The Journal of Geology, 70(4), 466-481. (Cited pages 1 and 3)

Ramsay, J. G., and M. I. Huber (1987), The techniques of modern structural geology, Volume 2: Folds and fractures, Academic Press, New York, 307 pp (Cited pages 5, 6, 7, and 8)

Røe, P., F. Georgsen, and P. Abrahamsen (2014), An Uncertainty Model for Fault Shape and Location, Mathematical Geosciences, 46(8), 957-969, doi: 10.1007/s11004-014-9536-z. (Cited page 2)

Shaw, J. H., A. Plesch, C. Tape, M. P. Suess, T. H. Jordan, G. Ely, E. Hauksson, J. Tromp, T. Tanimoto, R. Graves, K. Olsen, C. Nicholson, P. .J. Maechling, C. Rivero, P.Lovely, C. M. Brankman, and J. Munster (2015), Unified Structural Representation of the southern California crust and upper mantle, Earth and Planetary Science Letters, 415, 1-15, doi:10.1016/j.eps1.2015.01.016. (Cited page 1)

Thiessen, R. L., and W. D. Means (1980), Classification of fold interference patterns: a reexamination, Journal of Structural Geology, 2(3), 311-316. (Cited page 4)

Vollger, S. A., A. R. Cruden, L. Ailleres and E. J. Cowan (2015), Regional dome evolution and its control on ore-grade distribution: Insights from 3D implicit modelling of the Navachab gold deposit, Namibia, Ore Geology Reviews, 69 , 268-284, doi:10.1016/j.oregeorev.2015.02.020. (Cited page 1)

Wellmann, J. F., and K. Regenauer-Lieb (2012), Uncertainties have a meaning: Information entropy as a quality measure for 3-D geological models, Tectonophysics, 526, 207-216, doi:10.1016/j.tecto.2011.05.001. (Cited pages 1 and 10)

\section{Discrete lineAR TETRAHEDRAL SUPPORT}

The proposed modeling is implemented in the framework of discrete implicit modeling [Frank et al., 2007], where an interpolated scalar field $\varphi$ is mathematically represented by a piece-wise linear field based on a tetrahedron mesh. In this mesh, $\varphi$ is linearly interpolated from the four nodal values of each tetrahedral element.

We considering a tetrahedron, whose corners are indexed from 0 to 3 , with corner positions denoted $\left(\bar{x}_{i}, \bar{y}_{i}, \bar{z}_{i}\right)$ and nodal values are stored in the $\varphi_{c}$ vector. The scalar field is expressed as a linear function of $\bar{x}, \bar{y}$, and $\bar{z}$ :

$$
\varphi(\bar{x}, \bar{y}, \bar{z})=[1, \bar{x}, \bar{y}, \bar{z}] \cdot\left[a_{0}, a_{1}, a_{2}, a_{3}\right]^{t}
$$

After Frank et al. [2007], the coefficient $a_{i}$ are solution of the following equation:

$$
\left[\begin{array}{llll}
1 & \bar{x}_{0} & \bar{y}_{0} & \bar{z}_{0} \\
1 & \bar{x}_{1} & \bar{y}_{1} & \bar{z}_{1} \\
1 & \bar{x}_{2} & \bar{y}_{2} & \bar{z}_{2} \\
1 & \bar{x}_{3} & \bar{y}_{3} & \bar{z}_{3}
\end{array}\right] \cdot\left[\begin{array}{l}
a_{0} \\
a_{1} \\
a_{2} \\
a_{3}
\end{array}\right]=\left[\begin{array}{l}
\varphi_{c 0} \\
\varphi_{c 1} \\
\varphi_{c 2} \\
\varphi_{c 3}
\end{array}\right]
$$

This system can be solved for non-degenerated tetrahedron by inverting the left matrix, which defines the $\mathbf{M}$ matrix for Section 4.1 and the linear interpolation:

$$
\mathbf{M}=\left[\begin{array}{llll}
1 & \bar{x}_{0} & \bar{y}_{0} & \bar{z}_{0} \\
1 & \bar{x}_{1} & \bar{y}_{1} & \bar{z}_{1} \\
1 & \bar{x}_{2} & \bar{y}_{2} & \bar{z}_{2} \\
1 & \bar{x}_{3} & \bar{y}_{3} & \bar{z}_{3}
\end{array}\right]^{-1}
$$




$$
\varphi(\bar{x}, \bar{y}, \bar{z})=[1, \bar{x}, \bar{y}, \bar{z}] \cdot \mathbf{M} \cdot \varphi_{c}
$$

Based on Frank et al. [2007], a linear relation can also be written to define the constant gradient of a scalar field inside a given tetrahedron. This matrix referred to as $\mathbf{T}$ in this paper is defined as:

$$
\mathbf{T}=\left[\begin{array}{lll}
\left(\bar{x}_{1}-\bar{x}_{0}\right) & \left(\bar{y}_{1}-\bar{y}_{0}\right) & \left(\bar{z}_{1}-\bar{z}_{0}\right) \\
\left(\bar{x}_{2}-\bar{x}_{0}\right) & \left(\bar{y}_{2}-\bar{y}_{0}\right) & \left(\bar{z}_{2}-\bar{z}_{0}\right) \\
\left(\bar{x}_{3}-\bar{x}_{0}\right) & \left(\bar{y}_{3}-\bar{y}_{0}\right) & \left(\bar{z}_{3}-\bar{z}_{0}\right)
\end{array}\right]^{-1} \cdot\left[\begin{array}{cccc}
-1 & 1 & 0 & 0 \\
-1 & 0 & 1 & 0 \\
-1 & 0 & 0 & 1
\end{array}\right]
$$

